Int. J. Electrochem. Sci., 15 (2020) 1529 - 1538

\title{
High Performance Lithium-Sulfur Batteries Obtained by Employing Spiked Carbon Nanofibers as Host Materials
}

\author{
Jiaofei Huo ${ }^{1}$, Yinwei Wang ${ }^{2,3, *}$ \\ ${ }^{1}$ Department of Mechanical and Electrical Technology, Xijing University, Xi'an 710123, China \\ ${ }^{2}$ Intelligent Manufacturing Research and Development Center, Xijing University, Xi' an 710123, Chia \\ ${ }^{3}$ School of Mechanical Engineering, Xijing University, Xi'an 710123, China \\ *E-mail: yinweiwang@aliyun.com
}

doi: $10.20964 / 2020.02 .60$

Received: 17 October 2019 / Accepted: 5 December 2019 / Published: 31 December 2019

\begin{abstract}
Carbon materials have been considered as the most promising host materials for the sulfur in the past decades. Various carbon materials, including graphene, carbon sphere, carbon nanotube, prepared via different methods have been reported in the references, to improve the electrochemical performance of the lithium-sulfur batteries. In this paper, carbon nanofibers are first synthesized by electrospinning method. The as-prepared carbon nanofibers appear spiked carbon structure, which surface consists of branches. Due to the unique spiked club shape structure, the as-prepared carbon nanofiber sulfur composites display superior electrochemical activity with high specific capacity and long cycle performance. The initial specific capacity of the carbon nanofiber sulfur composites is as high as 1208 $\mathrm{mAh} / \mathrm{g}$. The capacity retention of the carbon nanofiber sulfur composites is $92 \%$ at $1 \mathrm{C}$ after 200 cycles.
\end{abstract}

Keywords: New Energy, Energy Storage System, Li-S Battery, Electric Vehicle, Cycle Stability

\section{$\underline{\text { FULL TEXT }}$}

(C) 2020 The Authors. Published by ESG (www.electrochemsci.org). This article is an open access article distributed under the terms and conditions of the Creative Commons Attribution license (http://creativecommons.org/licenses/by/4.0/). 